\title{
Is Bruxism A Risk Factor For Dental Implants?
}

\author{
Hassan H Koshak* \\ Periodontist and Implantologist, Saudi Arabia
}

Submission: September 23, 2017; Published: September 26, 2017

*Corresponding author: Hassan H Koshak, Head of the Dental Department and Dental Educator at Comprehensive Specialized Polyclinic, Ministry of Interior Security Forces Medical Services, Jeddah, Kingdom of Saudi Arabia, P.O. Box 108999, Jeddah 21352, KSA, Tel: +966 (0) 555507035 ;

Email: Koshak.hh@gmail.com

\section{Introduction}

The American Academy of Sleep Medicine defines bruxism as a stereotyped oral motor disorder characterized by sleep-related grinding and/or clenching of the teeth [1]. While the American Academy of Orofacial Pain has extended the definition to include the presence of the same characteristics during wakefulness [2].

\section{Complications}
a) Temporomandibular pain.
b) Tooth wear in the form of attrition.
c) Failure of dental restorations.
d) Loss of periodontal support.
e) Loss of dental implants [2].

\section{Etiology of bruxism}

Multifactorial

Medication, illegal drugs.

Genetics.

Trauma.

Neurological and psychiatric diseases.

Stress and personality are frequently mentioned.

Taken all evidence together, bruxism seems to be mainly regulated centrally, not peripherally.

Disturbances in the central dopaminergic system have been described in relation to bruxism [3].

According to Lobbezoo and Naeije, (2006), the main etiology of bruxism:
a) Morphological: $10 \%$.
b) Pathophysiological: $70 \%$.
c) psychosocial factors: $20 \%$.

Bruxism occurs due to an increase in the electromyographic activity of the masticatory muscles as a result of a sudden change in the depth of sleep from deeper to lighter sleep "Sleep Related Disorder" [4].

\section{Diagnosis}

Polysomnographic recording (PSG) is considered the gold standard, but it's main limitation:

a) High costs involved.

b) Shortage of adequately equipped sleep laboratories [1].

Clinical assessment, combined with the use of questionnaires, remains the most common diagnostic option for clinicians in the attempt to identify bruxers. Many of the questions are based upon the assumptions that bruxism activity produces:

a) Muscle pain/tenderness.

b) Manifests itself through sounds caused by tooth grinding [2].

The literature has shown that neither of these assumptions is necessarily true. At least $80 \%$ of episodes of bruxism do not produce noise [5]. Occlusal splints are currently used for the assessment of parafunctional habits [6].

\section{Signs of bruxism}

a) Muscle pain.

b) Tooth wear.

c) Tongue scalloping.

d) Masseter muscle hypertrophy [2].

\section{Bruxism and dental implants:}

a) Bruxism has been suggested to cause excessive overload on the implants and their super-structure.

b) Screw loosening, fracture.

c) Bone loss around the implant. 
d) Implant failure [4].

Tooth vs implant mobility (Table 1 ).

Table 1:

\begin{tabular}{|c|c|c|}
\hline & Apico-coronal (microns) & Bucco-lingual (microns) \\
\hline Tooth & $25-100$ & $56-108$ \\
\hline Implant & $3-5$ & $10-50$ \\
\hline
\end{tabular}

Unlike the tooth-periodontium interface, the implant bone interface lacks the ability to adapt reversibly to different loading conditions [6].

\section{Bruxism and dental implants:}

a) Occlusal overloading may cause micro-tissue damage that exceeds the capacity for repair leading to irreversible loss of bone support [2].

b) Forces developed during unconscious activities, on implants, which have reduced proprioception, reach levels of intensity so great as to constitute a real risk factor [7].

\section{Management of Bruxism}

Limiting the damage and effects that this disorder can have on the various structures of the stomatognathic system [1]. The use of occlusal splints in bruxers is logical for the purpose of:

a) Preventing tooth damage and wear.

b) Redistributing the articular loads.

c) Several studies have reported that nocturnal masseter EMG activity is reduced during treatment with occlusal stabilization splints [7].

In general, hard splints are preferable to soft resin ones, as the latter type may increase periodontal receptor stimulation and lead to an increase in EMG activity [8].

\section{A. Other proposed treatments:}
i. Drugs, anxiolytic and antidepressant.
ii. Botulinum toxin injections [2].

\section{Guidelines for implant therapy for bruxers}

Both surgical (number, size and position of implants) and the prosthetic (characteristics of the occlusal design) aspects of the intervention

\section{Guidelines:}

i. Increasing the number of supporting implants.

ii. Long, large-diameter implants may help to reduce the stress on peri-implant tissues.

iii. Splinted implants provide even distribution of the load.

iv. Avoid cantilevers. v. Non-axial loads should be avoided.

a) More freedom of movement (space) at the occlusal contact areas.

b) Flatter cuspal planes.

c) Hard occlusal splint [7].

Sleep dentistry (bruxism, snoring and sleep apnea), while not recognized as one of the nine dental specialties, qualifies for boardcertification by the American Board of Dental Sleep Medicine (ABDSM). The resulting Diplomate status is recognized by the American Academy of Sleep Medicine (AASM), and these dentists are organized in the Academy of Dental Sleep Medicine (USA). The qualified dentists collaborate with sleep physicians at accredited sleep centers and can provide oral appliance therapy and upper airway surgery to treat or manage sleep-related breathing disorders.

\section{Conclusion}

a) Only little research has focused upon the clinical approach to protect implant prostheses from bruxism.

b) The lack of well-designed clinical trials regarding the consequence of bruxism on implant prostheses poses a serious problem.

c) Thus, practical guidelines for the management of bruxism patients undergoing restorations using dental implants are based on expert opinions rather than on scientifically sound information.

\section{References}

1. Kato Takafumi, Taihiko Yamaguchi, Kazuo Okura, Susumu, Gilles J Lavigne (2013) Sleep less and bite more: Sleep disorders associated with occlusal loads during sleep. Journal of Prosthodontic Research 57: 69-81.

2. Shilpa Shetty, Varun Pitti, CL Satish Babu, GP Surendra Kumar, BC Deepthi (2010) Bruxism: A Literature Review. J Indian Prosthodont Soc 10(3): 141-148.

3. Daniela Feu, Fernanda Catharino, Catia Cardoso Abdo Quinta, Marco Antonio de Oliveira Almeida (2013) A systematic review of etiological and risk factors associated with bruxism. Journal of Orthodontics 40: 163-171.

4. Lobbezoo F, Van Der Zaag J, Naeije M (2006) Bruxism: its multiple causes and its effects on dental implants - an updated review. J Oral Rehabil 33(4): 293-300.

5. Lavigne GJ, Khoury S, Abe S, Yamaguchi T, Raphael K (2008) Bruxism physiology and pathology: an overview for clinicians. J Oral Rehabil 35(7): 476-494.

6. Manfredini D, Bucci MB, Sabattini VB, Lobbezoo F (2011) Bruxism: overview of current knowledge and suggestions for dental implants planning. Cranio 29(4): 304-312.

7. Chrcanovic, Bruno Ramos, Albrektsson, Tomas, Wennerberg (2015) Bruxism and Dental Implants: A Meta-Analysis. Implant Dentistry 24(5): 505-516.

8. Okeson JP (1987) The effects of hard and soft occlusal splints on nocturnal bruxism. J Am Dent Assoc 114(6): 788-779. 

CC Commons Attribution 4.0 License

DOI: $10.19080 /$ GJO.2017.11.555801
Your next submission with Juniper Publishers will reach you the below assets

- Quality Editorial service

- Swift Peer Review

- Reprints availability

- E-prints Service

- Manuscript Podcast for convenient understanding

- Global attainment for your research

- Manuscript accessibility in different formats

( Pdf, E-pub, Full Text, Audio)

- Unceasing customer service

Track the below URL for one-step submission https://juniperpublishers.com/online-submission.php 